\title{
Climate change, social vulnerability and child nutrition in South Asia
}

\author{
Kathryn McMahon \\ UNC-CH Department of Geography Honors Thesis
}

\begin{abstract}
$\underline{\text { Abstract }}$
Despite recent advancements in global economic and food security, climate change threatens to undermine child nutritional health, particularly for marginalized populations in tropical low- and middle-income countries, where temperatures are already high and community resources for responding to climate shocks are often few. Climate change in these places can damage crop yields, increase heat stress and infectious disease, and destabilize the economy, all of which puts children's nutritional health at risk. This is a major concern because adequate nutrition is central to the physical and cognitive development of children under five years old, and undernutrition in early life can cause damage that lasts well into adulthood. South Asia is at particular risk for climate-driven undernutrition due to a combination of extreme weather, existing nutritional deficits, and a lack of sanitation access. Previous studies have established that precipitation extremes in particular threaten to increase rates of undernutrition in this region, but the existing literature lacks adequate consideration of temperature anomalies, mediating social factors, and developmentally relevant timing of exposure to climate shocks. We combine highresolution temperature and precipitation data with household demographics and child anthropometry, using an approach that incorporates three key developmental periods and a rigorous fixed effects design. We find that temperature and precipitation extremes in the first year of life significantly increase the likelihood of stunting (height-for-age $z<-2$ ) for the majority of South Asian children. The detrimental effects of extreme precipitation are especially concentrated in under-resourced households, such as those lacking access to proper sanitation and education for women, while anomalous heat is particularly harmful for children in Pakistan. These results indicate that nutritional status in South Asia is highly responsive to climate exposures, and ongoing nutritional improvements in South Asia are likely to be handicapped as climate change leads to more frequent and intense climate shocks.
\end{abstract}

\section{Introduction}

Global economic wellbeing and food security have improved considerably over the past 50 years, but scholars are concerned that climate change will exacerbate recent trends towards deterioration, particularly for the world's most vulnerable populations (Burke et al. 2015). Among the most vulnerable are marginalized populations in tropical low- and middle-income countries, where baseline temperatures are high and community resources with which to respond are often few (IPCC, 2014; Frame et al. 2017; Mora et al. 2017). In these areas, population health and well-being are already threatened by rising global temperatures and increasingly variable rainfall patterns (Challinor et al. 2014; Mora et al. 2017; Spears et al. 2018), which in turn puts children's food security and nutritional health at particular risk. Adequate nutrition for children under five years old is recognized as central to development at the individual, national, and 
international levels (Horton, 2013), as chronic malnutrition in early childhood has been shown to cause irreparable damage to cognitive and physical development (Alderman, 2006; Black, 2013; Shively, 2017). Understanding the complex interactions between climate, nutrition, and social vulnerability in regions facing nutritional shortfalls is key to developing appropriate mitigation policy as the climate continues to cause more frequent and more intense extreme weather events (Frame et al. 2017).

Previous studies have examined the costs of precipitation extremes for child health at both the global and national scale (Arnell et al. 2016; Cooper et al. 2019; Frame et al. 2017; Grace et al. 2012; Kumar et al. 2016; Mora et al. 2017; Randell et al. 2020), but the role of childhood temperature exposures has been underexamined. Existing global and South Asian studies of climate shocks and childhood nutrition have instead focused exclusively on precipitation (Dimitrova \& Muttarak, 2020; Shively et al. 2015; Kumar et al. 2016; Tiwari et al. 2016; Cooper et al. 2019), ignoring the well-documented risks of temperature extremes (Davenport et al. 2016; Grace et al. 2021). Many studies have also not fully accounted for key biological periods of exposure to climate shocks, for potential vulnerability across different socio-demographic groups, or for spatial correlates of climate that might confound the results (Randell et al. 2020; Thiede \& Gray, 2020; Nicholas et al. 2021).

To address these issues, we use data from the Demographic and Health Survey Program (DHS) organized as part of the Integrated Public-Use Microdata Series (IPUMS) alongside temperature and precipitation data from the Climate Research Unit's Time-Series (CRU-TS) and the Climate Hazards Group Infrared Temperature \& Precipitation with Stations (CHIRPS \& CHIRTS) Datasets (Boyle et al. 2019; Harris et al. 2020; Funk et al. 2015; Funk et al. 2019). By combining these data, we are able to examine the effects of both climate anomalies and daily extremes on stunting and height-for-age for 222 thousand children ages 2-5 in South Asia. We separately examine climate exposures during the prenatal period, first year of life and second year of life, and use a fixed effects approach that accounts for both spatial and temporal confounders to climate. Our findings indicate that child growth in South Asia is undermined when the first year of life is unusually wet, hot or cold, as well as by the number of dry and unusually wet days in this period. We find that children with low toilet quality and low maternal education and who live in India are most vulnerable to these effects, as well as intriguing evidence for subpopulations that initially benefit from higher temperatures. Taken together, these results indicate that nutritional status in South Asia is highly responsive to climate exposures and that ongoing nutritional improvements in South Asia are likely to be handicapped as climate change leads to more frequent and intense precipitation shocks.

\section{Background}

Over the past decade, a rich literature has established that global climate change affects health in powerful and calculable ways. Although much of this research focuses on high-income countries in Europe and North America, evidence shows that the consequences of climate change will emerge more quickly and be more virulent in countries closest to the equator (IPCC, 2014; 
Frame et al. 2017; Mora et al. 2017). The literature has also established that nutritional health is highly vulnerable to environmental stressors in early childhood, which take their toll through heat stress, failing agriculture, the spread of disease, and household economic instability (Challinor et al. 2014; Burke et al. 2015; Spears et al. 2018). In particular, we know that children's vulnerability to climate shocks does not remain constant throughout their early years (Shrimpton et al. 2001, Victora et al. 2009, Headey et al. 2015); evidence shows that exposure to extreme weather during the first 1,000 days after conception can have adverse developmental effects that last into adulthood and are linked to educational, financial, and physical deficits (Rayco-Solon et al. 2005; Alderman, 2006; Ramakrishnan et al. 2012; Black, 2013; Nobles \& Hamoudi, 2019). A handful of studies have taken this into account when examining the intersection of climate change and child malnutrition (Kumar et al. 2016; Randell et al. 2020, Grace et al. 2021; Nicholas et al. 2021) but the existing literature is largely lacking in consideration of timing of exposure. We address this gap by measuring exposure and subsequent nutritional outcomes for the prenatal period as well as the first and second years of life.

In general, scholars agree that warming trends - particularly in conjunction with drynessincrease rates of stunting in children under five, an important indicator of chronic undernutrition (Grace et al. 2012; Davenport et al. 2016; Randell et al. 2020; Thiede \& Gray, 2020). The impacts of precipitation extremes are less clear-cut; periods of drying have been found to cause undernutrition in some studies (Hoddinott \& Kinsey, 2001; Grace et al. 2012; Davenport et al. 2016; Kumar et al. 2016), while others have noted that excessive rain is more strongly associated with stunting (Del Ninno \& Lundberg, 2005; Dimitrova \& Muttarak, 2020; Thiede \& Gray, 2020). Cooper et al. (2019) explored the nutritional effects of both precipitation extremes in 53 countries and found that while children's heights steadily declined as conditions got drier, they declined even more steeply during wet periods - but only when the rain was very extreme. Others have found mixed effects of climate shocks that vary significantly according to spatial location, demographic characteristics, and timing of exposure (Shively et al. 2015; Grace et al. 2021; Nicholas et al. 2021). In linking climate with birth outcomes in Mali, Grace et al. (2021) found that precise metrics and consideration of exposure timing - down to the trimester level, for prenatal exposure - are especially important when analyzing the impacts of precipitation. Still other researchers have connected the timing of yearly monsoons with child undernutrition, finding that higher precipitation was good for health during the rainy agricultural season, while delays in rain onset increases stunting by harming harvests, agricultural livelihoods, and subsequent food security (Randell et al. 2020; Thiede \& Gray, 2020).

A related body of literature has identified South Asia as a region where children's health is particularly vulnerable to climate change due to a unique combination of extreme weather, existing nutritional deficits, and a lack of sanitation access. In quantifying India's vulnerability to rising global temperatures, Lopalo et al. (2018) estimate that the damages of a business-as-usual scenario would be equivalent to a $29 \%$ per capita reduction in national GDP for twenty consecutive years, an effect which would be barely mitigated even if India ceased all greenhouse gas emissions immediately. This evidence drives home the fact that, however severe the negative impact of global climate change, high-temperature low- and middle-income regions like South Asia will bear the brunt of it. Up to now, precipitation shocks have been the primary focus of 
studies that explicitly seek to link climate events with child nutritional outcomes in South Asia (Del Ninno \& Lundberg, 2005; Shively et al. 2015; Kumar et al. 2016; Tiwari et al. 2016). Evidence from this work shows that both extremes are bad for child health: early exposure to drought increases children's risk of stunting and mortality in rural India (Kumar et al. 2016), as do flood events in both Nepal and Bangladesh (Del Ninno \& Lundberg, 2005; Tiwari et al. 2016). The current study also considers the impacts of extreme precipitation but expands on previous research by jointly considering both wetness and dryness using in a nonlinear approach (Cooper et al. 2019), and by including temperature anomalies, whose impacts have been understudied thus far (Randell et al. 2020; Thiede \& Gray, 2020).

Our data and methods partially resemble those employed in several other existing studies that consider South Asia (Kumar et al. 2016; Cooper et al. 2019; Dimitrova \& Muttarak, 2020), but with several key distinctions. Both Cooper et al. (2019) and Dimitrova \& Muttarak (2020) use DHS survey data to measure height-for-age (HAZ), and the latter group specifically analyzes the 2014-15 Indian wave. Although we forgo using GPS coordinates, we extend the range of our study by including the three previous waves in India as well as ten total from Pakistan, Nepal, and Bangladesh. Dimitrova \& Muttarak (2020) also use CRU climate data, although they exclude climate data outside of the annual monsoon period, whereas we measure children's exposure to climate anomalies year-round. We also consider daily climate extremes as well as monthly anomalies, thereby increasing the temporal resolution of our study relative to others that use monthly or yearly climate data only. Finally, none of the aforementioned studies consider the impact of temperature shocks on child nutrition, perhaps making this our largest contribution to collective understanding of the impacts of a warming world on populations in this tropical region.

Although a growing literature has linked extreme weather and negative nutritional outcomes, one difficulty comes in identifying the precise mechanisms through which climate and child health interact. Some additional studies have explored this conundrum, and have identified potential avenues of explanation. In a recent publication, Randell et al. (2020) outline four of these pathways: agricultural livelihoods, heat stress, infectious disease transmission, and women's time use (their own addition). When weather conditions are not conducive to crop growth, agricultural households lose crucial income and food security, even under projected scenarios that include stringent carbon reductions (Challinor et al. 2014; Hasegawa et al. 2018; Ray et al. 2019). Lasting high temperatures can impair fetal development and threaten the shared nutritional health of mothers and babies, which is especially delicate during the first 1,000 days of life (Rayco-Solon et al. 2005; Ramakrishnan et al. 2012). Warming also increases the range of vector-borne diseases, which weaken children's immune systems and prevent proper nutrition (Pruss-Ustun et al. 2008; Spears et al. 2018). Infants whose mothers must perform demanding physical work during pregnancy are at higher risk of low birthweights and subsequent stunting (Randell et al. 2020). Each of these is connected to child nutrition via changes in household health and economic security, and these pathways may often intersect or work in tandem with each other. 
Strong evidence also exists to suggest that nutritional deficits among South Asian children can be partly explained by the interactions of poor sanitation, gender inequality, and infectious disease. Spears et al. (2018) argue that exposure to open defecation alone can account for the fact that the average person from India is richer but shorter than the average person from SubSaharan Africa - a phenomenon often called the "Asian enigma". Toilet access is a key social determinant of nutritional health because germs in feces cause infectious diseases, often diarrheal, which prevent children from absorbing nutrients and energy from their food and leave them susceptible to further infections (Pruss-Ustun et al. 2008; Spears et al. 2018). The prevalence of open defecation is also closely connected to gender roles and equity in South Asia. In rural Uttar Pradesh, low-caste women with no household toilet access were forced to search for remote (and often dangerous) open defecation sites for fear of being seen by men, a fact which was associated with weakness in pregnant mothers and infants alike (Khanna \& Das, 2015). Similarly, researchers found that the children of women with low social status were shorter on average than their high-status counterparts, further suggesting a link between maternal status, malnutrition, and subsequent child health (Coffey et al. 2015). The current study will advance this avenue of research by bringing climate into the mix - will the effects of temperature and precipitation extremes be compounded by lack of toilet access? This is a novel question which no previous study has directly tested.

\section{$\underline{\text { Data and Methods }}$}

This study draws on cross-sectional and nationally representative data from the Demographic and Health Surveys (accessed via IPUMS-DHS) on child undernutrition in four South Asian countries (Bangladesh, India, Nepal, and Pakistan). DHS administers structured surveys using a standardized sample design, questionnaire, and implementation procedure (Boyle et al. 2019). This study includes all DHS rounds in these countries that collected child anthropometric data, totaling 18 rounds conducted since the 1990s and including six rounds in Bangladesh (1996-97, 1999-2000, 2004, 2007, 2011, 2014), four in India (1992-93, 1998-99, 2005-06, 2015-16), five in Nepal (1996, 2001, 2006, 2011, 2016) and three in Pakistan (1990-91, 2012-13, 2017-18). In these surveys, nationally representative household samples were selected via stratified, multi-stage sampling designs, with enumeration areas as the smallest areal unit. We include sampling weights in all multivariate analyses in order to account for the clustered sampling design as well as an imbalance of observations across time and space, with the 2015-16 Indian survey round making up over half of all observations $(137,824)$. GPS locations of enumeration areas are only available for 10 of 18 rounds, but we are able to locate households in 41 time-standardized administrative units using shapefiles created by the IPUMS-DHS project (Figure 1). These spatial units (5 each in Bangladesh, Nepal, and Pakistan, and 26 in India) are roughly equivalent to provinces and we refer to them as such. We exclude four provinces (Gilgit Baltistan; Federally Administered Tribal Areas; and Azad, Jammu and Kasmir in Pakistan; Puducherry in India) because they were included in only one DHS round, making it impossible to compare survey results across time. From these provinces and survey rounds, we extract data on 222,572 children ages 24-59 months, the ages at which stunting becomes evident (Alderman $\&$ Headey, 2018). We focus on children's exposure to climate extremes during the prenatal 
period and first 2 years of life, as these are the primary years during which children experience growth faltering (Shrimpton et al. 2001; Victora et al. 2009; Headey et al. 2015) and nutrition during this period has been shown to be a strong indicator of health and development well into adulthood (Rayco-Solon et al. 2005; Ramakrishnan et al. 2012).

Our primary interest is the relationship between climate anomalies and height-for-age (HAZ), but we also include a set of control variables to account for the most commonly identified socio-demographic characteristics of children, mothers, and households that contribute to undernutrition. Maternal controls are mother's age at childbirth, marital status, level of education and total number of children ever born; child controls are sex, age, month of birth, place of birth (health clinic or other), and birth order; and household controls include both household and community access to improved toilet infrastructure (such as flush toilets, pit latrines, or other improved non-flushing toilet system), as well as urban-rural status (Boyle et al. 2019). There is some variation in the metric for urban-rural status between countries in our sample because DHS uses local definitions of urbanicity, but at minimum each country considers any place with a municipality, town committee, or cantonment board to be urban (Boyle et al. 2019). By controlling for child age and sex we account for biological factors influencing child anthropometry (Ssewanyana, 2003; Shrimpton et al. 2012), whereas our maternal and household controls add consideration of availability and allocation of family resources that have the potential to affect nutrition (De Silva \& Sumarto, 2018). We add squared terms for children's and mothers' ages (in months and years, respectively) to allow their effect on child nutrition to be nonlinear (Victoria et al. 2010). Month and place of child's birth further account for the influence of both seasonality and health at birth (Lokshin \& Radyakin, 2012). Missing values on "born in clinic" are accounted for by including a missing indicator in the regression. This study focuses predominantly on stunting, not wasting, because stunting is indicative of long-term malnutrition (Dearden et al. 2017). A child whose HAZ is less than two standard deviations below the mean is considered to be stunted, while a HAZ value less than three standard deviations below the mean implies severe stunting.

To measure climate exposures, we first extract data on monthly mean temperature and precipitation rate from the Climate Research Unit (CRU), a project of the University of East Anglia. CRU collects data from weather stations around the world and then uses a spatial interpolation approach to create a global gridded dataset at $0.5^{\circ}$ degree resolution (Harris \& Jones, 2020), a pixel size which is small relative to our provinces. We then use the timestandardized shapefiles described above to extract the spatial mean of temperature and precipitation values in each month from 1981-2018. In each province, we then create running 9month and 12-month means and standardize these into temperature and precipitation anomalies using the historical mean and the historical standard deviation in each province for this running length. Relative to raw climate values, standardized climate anomalies have multiple advantages for analyses of climatic impacts on health: they are locally-meaningful deviations from familiar conditions, they can be interpreted as exogenous shocks, and they are stronger predictors of 
social outcomes (Gray \& Wise, 2016; Nordkvelle, Rustad, \& Salmivalli, 2017). We then link the nine-month anomalies to the prenatal period of each child ( 9 months before birth to the month before birth) based on their month of birth and province of residence, and similarly link the 12month anomalies to the first (0-11 months) and second (12-23) year of life of each child. This generates six climate values for each child: the standardized temperature and precipitation anomalies observed in the prenatal period, the first year of life and the second year of life. These periods correspond to the first 1000 days of life, the key period of child development (Schwarzenberg \& Georgieff, 2018).

We supplement these measures using data on daily maximum temperature and precipitation rate with a pixel size of $0.05^{\circ}$ degrees. These temperature (precipitation) data come from the Climate Hazards Group Infrared Temperature (Precipitation) with Stations (CHIRTS and CHIRPS, respectively) datasets. CHIRTS and CHIRPS are high resolution, semi-global $\left(50^{\circ} \mathrm{S}-50^{\circ} \mathrm{N}\right)$ data products created by a combination of satellite estimates and in situ observations (Funk et al. 2015; Davenport et al. 2017; Funk et al. 2019). We extract these daily data using the same time-standardized shapefiles and process described above for the years 1983-2016. Because CHIRTS is currently only available up to 2016, we exclude children who turned age 2 after December $2016(\mathrm{~N}=626)$ from the supplementary analysis including these measures. We use the CHIRPS and CHIRTS values to generate counts of the number of extreme days (extremely hot, extremely wet, extremely cold, and extremely dry) in each of the three developmental periods described above. In this study, a day is considered extremely hot if it is above the $95^{\text {th }}$ percentile for temperatures in a given province, relative to the entire temperature record (1983-2016). Similarly, an extremely wet day must exceed the $95^{\text {th }}$ percentile for precipitation relative to the same time period, whereas a cold day is below the $5^{\text {th }}$ percentile and a dry day is any day with zero precipitation, the lower bound for this value. The supplementary specification includes twelve new variables for each child: a count of extreme hot, wet, cold, and dry days for each of the prenatal period, the first year of life, and the second year of life.

With the climate and survey data thus linked, we use fixed effects regression to examine how child height is influenced by temperature and precipitation while accounting for potential spatial and temporal confounders. Using CRU anomalies in Specification 1 and CHIRPS/CHIRTS extreme days in Specification 2, we model HAZ using linear regression and then stunting and severe stunting using logistic regression. Coefficients from the logistic regression are presented as odds ratios, which can be interpreted as the multiplicative effects of a one unit increase in the predictor on the odds of the outcome. All models include the following predictors: the climate exposures defined above, the socio-demographic controls defined above (including a missing indicator for born in clinic), fixed effects for provinces, and a linear time trend for the survey year. We also correct for clustering at the level of the province and include sampling weights as described above. The inclusion of fixed effects for the province accounts for all baseline differences between provinces including historical climate, whereas the inclusion the of the time trend accounts for linear changes in nutrition over time as a result of macro-changes 
such as urbanization and development. Additionally, the correction for clustering accounts for non-independence and shared environmental exposures within provinces, whereas the sampling weights account for non-equal sampling probabilities. We subsequently extend this analysis, using Specification 1, by (1) allowing the climate effects to be nonlinear by adding the square of the anomalies (a quadratic specification), and (2) allowing four socio-demographic characteristics (improved toilet access, maternal education level, caste/tribe - for India only) to modify the climate effects by adding interactions with these variables, one set at a time.

\section{$\underline{\text { Results }}$}

Table 1 contains unweighted descriptive statistics for all analytical variables. The dependent variables are the child anthropometric measures (HAZ, stunting, and severe stunting), and independent variables include climate anomalies and extreme days for the three relevant developmental periods (including raw climate values for context) as well as socio-demographic controls. Several socio-demographic characteristics point to high rates of poverty and deprivation in this sample. For instance, $38 \%$ of mothers had received no formal education at the time of interview, and only a small majority of households (56\%) had access to improved toilet infrastructure. Additionally, $73 \%$ of households were classified as rural by DHS, suggesting a reliance on agriculture for family income and food security. It is also notable that the means for both precipitation and temperature anomalies are positive for all identified exposure periods, implying that recent conditions in South Asia have been both somewhat hotter and wetter than their historical means, though with many values in the cool and dry range. Perhaps most importantly, Table 1 reveals very high rates of child stunting across our sample, with half (47\%) of all children classified as stunted and $21 \%$ as severely stunted.

Figure 1 shows the proportion of children in each study province who were stunted at the time of the most recent DHS interview, spanning 2014-2018 across countries. Across the sample, only four Indian provinces (Punjab and Chandigarh, Goa, Tamil Nadu, and Kerala and Lakshadweep) have stunting rates under $27 \%$, while every country has at least one province with a stunting rate over $50 \%$. The seven provinces of highest child malnutrition fall in eastern Bangladesh, mid-western Nepal, north and northeastern India, and far-western Pakistan (including the major city of Karachi), and are home to hundreds of millions of people.

Table 2 displays the effect of early exposure to climate anomalies (Specification 1), extreme days (Specification 2), and potential confounders (displayed for Specification 1) on HAZ, stunting, and severe stunting in South Asia for children aged 2-5. The climate effects are jointly significant for all three of these outcomes under both climate specifications. Under Specification 1 , neither temperature nor precipitation anomalies experienced during the prenatal period have a significant effect on child height, and the impact instead occurs during the first and second years of life. A one unit increase in the precipitation anomaly (equivalent to one standard deviation of precipitation) during the first year of life increases the odds of stunting by $3.1 \%(\mathrm{p}=0.001)$ and severe stunting by $2.4 \%$ ( $\mathrm{p}=0.038)$. Meanwhile, every additional unit of second year precipitation increases the odds of severe stunting by $3.1 \%(\mathrm{p}=0.033)$; however there is not a significant effect of second year precipitation on either HAZ or stunting. In contrast to precipitation's detrimental 
impacts, we find a marginally and inconsistently significant positive relationship between anomalous heat during the first and second years of life and improved nutritional outcomes at ages 2-5 years. One additional unit of heat decreases the likelihood of stunting by $3.4 \%$ $(\mathrm{p}=0.078)$ and increases HAZ by $2.7 \%(\mathrm{p}=0.055)$ when the anomaly occurs during the first and second years, respectively.

Consistent with Specification 1, the extreme days specification reveals that child heights are more reactive to precipitation shocks than to temperature extremes. Most notably, extreme wet days and dry days during the first year of life are both strongly associated with decreases in HAZ as well as increases in stunting and severe stunting. When exposure occurs in the second year, however, dry days tend to improve nutritional outcomes - every additional dry day decreases the average child's likelihood of stunting by $0.2 \%(\mathrm{p}=0.005)$. We also find that every additional wet day during the prenatal period decreases the average child's HAZ by $0.3 \%(p=0.003)$, though this effect does not carry over to stunting and severe stunting. Finally, the only temperature effect we observe under specification 2 is a $0.4 \%(\mathrm{p}=0.009)$ reduction in severe stunting odds with every additional cold day experienced during the first year of life.

In addition to these climate effects, Table 2 also reveals that many of our control variables also have statistically significant effects on HAZ, stunting, and severe stunting in the expected directions. Indicators of wealth, such as maternal education, access to health clinics for childbirth and access to improved toilets, predict higher HAZ and lower rates of stunting and severe stunting when compared to reference categories $(p<0.001)$. The prevalence of child stunting and severe stunting also significantly declines with mother's age. With each additional year of a mother's age at childbirth, her child is $8.9 \%$ less likely to be stunted when they are 2-5 years old $(p=0.000)$. Finally, it is notable that the children of rural households are $9.6 \%$ more likely to be stunted than their urban counterparts $(\mathrm{p}=0.001)$, though the significance of this relationship does not extend to severe stunting.

The results in Table 2 implicitly assume that climate's effects on child nutrition are linear. For instance, if a rise in precipitation increases the probability of stunting then a decline in precipitation must decrease it. To relax this assumption, Figure 2 displays predicted probabilities from a supplemental specification that includes a squared term for each climate variable, e.g. a quadratic transformation, focusing on stunting. Here, we display only those results for which the linear and squared terms are jointly significant, in this case both for the first year of life. The first panel of Figure 2 shows that both first-year temperature extremes tend to increase the likelihood of child stunting, though the margin of error is greater for cold temperatures than for heat as the former have been relatively uncommon during our study period. In contrast, the first-year precipitation anomaly has an approximately linear positive effect on stunting, reinforcing the results in Table 1.

Presented in Table 3, we also use logistic regression to examine interactions between climate anomalies and four key socio-demographic variables (household toilet quality, mother's education level, country of residence, and caste/tribe among Indian children), again focusing on stunting as the outcome. Joint significance tests reveal that each of these variables significantly modifies the impacts of climate on child nutrition. While children with improved toilet systems 
experience no effect of climate anomalies, children with unimproved toilets tend to benefit from heat anomalies and suffer from exposure to extreme precipitation. Interestingly, the magnitude of the temperature effect increases with the age of exposure; with each additional unit of heat during the prenatal, first year, and second year periods, children with unimproved household toilets are $3 \%(\mathrm{p}=0.018), 3.2 \%(\mathrm{p}=0.078)$, and $5.3 \%(\mathrm{p}=0.011)$ less likely to be stunted, respectively. Conversely, precipitation anomalies during the first and second years of life increase stunting among children with unimproved toilets by $4.2 \%(\mathrm{p}=0.000)$ and $4 \%(\mathrm{p}=0.018)$, though prenatal precipitation anomalies break this trend with a marginally significant reduction of stunting ( $\mathrm{p}=0.098)$. In keeping with these trends, the height-for-age of children with no maternal education (another indicator of poverty) are most reactive to climate anomalies. Compared with the children of higher-educated mothers, those of lower-educated mothers tend to be more vulnerable to the negative effects of extreme precipitation in the first year of life, and benefit more from the positive effects of heat across all developmental periods. Here, however, we find stronger significance in the relationship between prenatal precipitation anomalies and reduced stunting $(\mathrm{p}=0.008)$ and no clear relationship between second year precipitation and child height.

Next, the interaction between climate and country of residence reveals that climate's effects on child stunting are most pronounced in India and Pakistan, and there is not a clear relationship between climate and nutrition in Bangladesh. From these results, it appears that the prenatal precipitation effect observed in previous interactions can be attributed largely to India, where one unit increase in precipitation anomaly reduces the average child's odds of stunting by $1.7 \%$ $(p=0.035)$. On the other hand, exposure to heat in any developmental period has a much stronger detrimental health effect in Pakistan than those living in any other country. An additional unit of temperature anomaly increases the average Pakistani child's odds of being stunted by $35.9 \%$ $(\mathrm{p}=0.000)$ if exposure occurs in the first year of life, and $13 \%(\mathrm{p}=0.01)$ for the second-year exposure. Meanwhile, first and second year heat exposure actually reduces the odds of stunting for children in India and Nepal, respectively; this division may explain the low magnitude and significance of the first and second year temperature effect in the main model. Finally, the interaction between climate anomalies and caste/tribe in India $(\mathrm{N}=184,176)$ reveals that children of mothers belonging to scheduled castes and scheduled tribes tend to be more vulnerable to the detrimental effects of extreme precipitation during the first and second years of life, while those whose mothers do not belong to these groups tend to benefit more from anomalous heat. In the second year of life, for instance, every additional unit of precipitation anomaly increases odds of stunting by $7 \%(\mathrm{p}=0.043)$ and $8.5 \%(\mathrm{p}=0.045)$ for children of mothers from scheduled castes and scheduled tribes, respectively. Other Indian children are not significantly impacted by second year precipitation anomaly. Instead, they experience an $8.5 \%$ decrease $(p=0.000)$ in the odds of stunting for every additional unit of second year temperature anomaly - a benefit that does not extend to children of women from scheduled castes and tribes.

\section{$\underline{\text { Discussion }}$}

Our results show that precipitation extremes during the first year of life increase child stunting in South Asia. This particular and wide-reaching vulnerability to precipitation shocks in 
the first year may reflect the delicacy of nutritional health immediately after birth, when maternal and infant nutrition are still very closely linked and infants are being exposed to complex disease environments for the first time. For instance, infants ages 0-1 years may be more likely than other children to suffer from diarrheal disease and subsequent impaired nutrition after periods of heavy rainfall, which can contaminate drinking water (Carlton et al. 2014). To better understand this mechanism, future studies should bring in additional survey data in order to directly test the relationship between rainfall and diarrheal disease. We also find that the impacts of first year precipitation shocks are most pronounced in children who live in India, whose mothers have no education, or who do not have access to an adequate toilet. The latter two characteristics, both indicators of low socio-economic status, are likely correlated with increased odds of exposure to contamination. Indian children may be similarly vulnerable to contamination and disease due to high rates of open defecation. In 2012, the WHO estimated that India accounted for $90 \%$ of the nearly 700 million people who practice open defecation in South Asia, and nearly 50\% of Indian children in our sample had inadequate toilet access (UNICEF \& WHO, 2012). Taken together, these results support previous connections drawn between flooding and undernutrition in this region (Del Ninno \& Lundberg 2005; Tiwari et al. 2016) and complement existing evidence that sanitation access and social status play a significant role in determining nutritional outcomes in this region (Coffey et al. 2015; Khanna \& Das, 2015; Spears et al. 2018).

Temperature anomalies appear to have a weaker effect than precipitation in our sample, but we find evidence that both temperature extremes in the first year of life threaten to undermine child nutritional health (Figure 2). While the overall effects of temperature shocks are negative, we also find some intriguing evidence that a warming climate may counteract the deleterious effects of precipitation anomalies in certain subpopulations of South Asian children. For children with unimproved toilets and uneducated mothers - the same children who were most at risk of stunting after exposure to extreme rain - anomalous heat in any developmental period reduced the odds of stunting in a significant or marginally significant way. Temperature's impacts on nutrition also vary significantly by country; Pakistani children in our sample are highly vulnerable to heat, while Indian children may benefit from warming. These variable temperature effects are consistent with other studies that have found child height to be both positively and negatively associated with temperature anomalies, possibly reflecting the fact that initial warming may result in some benefits for local agriculture (Nicholas et al. 2021; Randell et al. 2020). Indeed, the existing literature on climate change's agricultural impacts in this region notes climate change's mixed effects on South Asian crop yields to date (Ray et al. 2019). As temperatures continue to increase, however, the harmful effects of climate change on agricultural production will likely become more pronounced, further threatening food security and child nutrition in this region.

Our findings hold implications for future studies of climate and child nutrition in South Asia, as well as for the future of climate change policy and mitigation in this region. First, we find that multiple social factors (toilet access, maternal education status, country, and caste/tribe) significantly modify climate's effects on stunting, suggesting that the human impacts of climate change will be highly heterogonous in South Asian populations. Therefore, future research of this topic should continue to take advantage of integrated data sources and a rigorous fixed 
effects design in order to isolate the climate effect and identify key social mediators. Researchers should also direct greater attention toward temperature extremes associated with climate change and their short- and long-term effects on agricultural systems, food and economic security, and human health South Asia. Though our findings suggest that warming in the short-term may have some positive effects in certain subpopulations, we expect that the long-term, big-picture effects of rising temperatures will include increased stunting rates in this region. However, additional research is necessary to accurately characterize these relationships and predict future health outcomes under further climate change. Finally, because we do not account for migration in this study, we cannot identify households that may have moved to another province after experiencing a climate exposure and before the time of interview. To eliminate this source of potential endogeneity, future studies should utilize survey questions that address migration or longitudinal datasets where possible.

In the context of the existing literature, our findings increase awareness and concern that temperature and precipitation shocks during early life threaten to undermine child growth trajectories in South Asia. The most imminent and alarming risks include those of extreme heat in Pakistan and extreme first-year rain in India. Furthermore, our results suggest that the most vulnerable children - those belonging to under-resourced households — will suffer the highest rates of climate-driven undernutrition. Mitigation efforts and material resources are therefore likely to be the most impactful if they are focused primarily in these vulnerable communities. We also find compelling evidence that access to improved toilets can go a long way towards protecting children against the deleterious effects of climate change, which is an encouraging backdrop for future and ongoing policy efforts to increase toilet and sanitation access in South Asia.

\section{Acknowledgements}

This project received support from the Office of Undergraduate Research and Summer School at the University of North Carolina at Chapel Hill, as well as the Alexandre Honors Carolina Expendable Fund administered by Honors Carolina. 


\section{References}

1. Alderman, H., \& Headey, D. (2018). The timing of growth faltering has important implications for observational analyses of the underlying determinants of nutrition outcomes. PloS one, 13(4), e0195904.

2. Alderman, H., Hoddinott, J., \& Kinsey, B. (2006). Long term consequences of early childhood malnutrition. Oxford economic papers, 58(3), 450-474.

3. Arnell, N. W., Brown, S., Gosling, S. N., Gottschalk, P., Hinkel, J., Huntingford, C., \& Osborne, T. M. (2016). The impacts of climate change across the globe: a multi-sectoral assessment. Climatic Change, 134(3), 457-474.

4. Boyle, E.H.; King, M.; Sobek, M. (2019). IPUMS-Demographic and Health Surveys: Version 7. Minnesota Population Center and ICF International, https://doi.org/10.18128/D080.V7

5. Black, R. E., Victora, C. G., Walker, S. P., Bhutta, Z. A., Christian, P., De Onis, M., ... \& Uauy, R. (2013). Maternal and child undernutrition and overweight in low-income and middle-income countries. The lancet, 382(9890), 427-451.

6. Burke, M., Hsiang, S. M., \& Miguel, E. (2015). Global non-linear effect of temperature on economic production. Nature, 527(7577), 235.

7. Carlton, E. J., Eisenberg, J. N., Goldstick, J., Cevallos, W., Trostle, J., \& Levy, K. (2014). Heavy rainfall events and diarrhea incidence: the role of social and environmental factors. American journal of epidemiology, 179(3), 344-352.

8. Challinor, A. J., Watson, J., Lobell, D. B., Howden, S. M., Smith, D. R., \& Chhetri, N. (2014). A meta-analysis of crop yield under climate change and adaptation. Nature Climate Change, 4(4), 287.

9. Cooper, M. W., Brown, M. E., Hochrainer-Stigler, S., Pflug, G., McCallum, I., Fritz, S., Silva, J \& Zvoleff, A. (2019). Mapping the effects of drought on child stunting.

Proceedings of the National Academy of Sciences, https://doi.org/10.1073/pnas.1905228116

10. Davenport, F., Grace, K., Funk, C., \& Shukla, S. (2017). Child health outcomes in subSaharan Africa: A comparison of changes in climate and socio-economic factors. Global Environmental Change, 46, 72-87.

11. Dearden, K. A., Schott, W., Crookston, B. T., Humphries, D. L., Penny, M. E., \& Behrman, J. R. (2017). Children with access to improved sanitation but not improved water are at lower risk of stunting compared to children without access: a cohort study in Ethiopia, India, Peru, and Vietnam. BMC public health, 17(1), 1-19.

12. Del Ninno, C., \& Lundberg, M. (2005). Treading water: the long-term impact of the 1998 flood on nutrition in Bangladesh. Economics \& Human Biology, 3(1), 67-96.

13. De Silva, I., \& Sumarto, S. (2018). Child malnutrition in Indonesia: can education, sanitation and healthcare augment the role of income?. Journal of International Development, 30(5), 837-864.

14. Dimitrova, A., \& Muttarak, R. (2020). After the floods: Differential impacts of rainfall anomalies on child stunting in India. Global Environmental Change, 64.

15. Frame, D., Joshi, M., Hawkins, E., Harrington, L. J., \& de Roiste, M. (2017). Populationbased emergence of unfamiliar climates. Nature Climate Change, 7(6), 407. 
16. Funk, C., Peterson, P., Landsfeld, M., Pedreros, D., Verdin, J., Shukla, S., ... \& Michaelsen, J. (2015). The climate hazards infrared precipitation with stations - a new environmental record for monitoring extremes. Scientific data, 2(1), 1-21.

17. Funk, C., Peterson, P., Peterson, S., Shukla, S., Davenport, F., Michaelsen, J., ... \& Mata, N. (2019). A high-resolution 1983-2016 T max climate data record based on infrared temperatures and stations by the climate Hazard center. Journal of Climate, 32(17), 56395658.

18. Grace, K., Davenport, F., Funk, C., \& Lerner, A. M. (2012). Child malnutrition and climate in Sub-Saharan Africa: An analysis of recent trends in Kenya. Applied Geography, 35(1-2), 405-413.

19. Grace, K., Verdin, A., Dorélien, A., Davenport, F., Funk, C., \& Husak, G. (2021). Exploring Strategies for Investigating the Mechanisms Linking Climate and IndividualLevel Child Health Outcomes: An Analysis of Birth Weight in Mali. Demography.

20. Gray, C., \& Wise, E. (2016). Country-specific effects of climate variability on human migration. Climatic change, 135(3-4), 555-568.

21. Harris I, Osborn TJ, Jones P and Lister D (2020) Version 4 of the CRU TS Monthly High-Resolution Gridded Multivariate Climate Dataset. Sci Data 7,, 109 (2020). https://doi.org/10.1038/s41597-020-0453-3

22. Horton, R., Lo, S., Lemma, F., Matji, J., Pinstrup-Andersen, P., \& Nabarro, D. (2013). Nutrition: a quintessential sustainable development goal. Lancet Series Maternal Child Nutr.

23. Headey, D., Hoddinott, J., Ali, D., Tesfaye, R., \& Dereje, M. (2015). The other Asian enigma: explaining the rapid reduction of undernutrition in Bangladesh. World Development, 66, 749-761.

24. Hoddinott, J., \& Kinsey, B. (2001). Child growth in the time of drought. Oxford Bulletin of Economics and statistics, 63(4), 409-436.

25. IPCC, 2014: Climate Change 2014: Synthesis Report. Contribution of Working Groups I, II, and III to the Fifth Assessment Report of the Intergovernmental Panel on Climate Change. IPCC, Geneva, Switzerland.

26. Khanna, T., \& Das, M. (2016). Why gender matters in the solution towards safe sanitation? Reflections from rural India. Global public health, 11(10), 1185-1201.

27. Kumar, S., Molitor, R., \& Vollmer, S. (2016). Drought and early child health in rural India. Population and Development Review, 53-68.

28. Lokshin, M., \& Radyakin, S. (2012). Month of birth and children's health in India. Journal of Human Resources, 47(1), 174-203.

29. Lopalo, M., Kuruc, K., Budolfson, M., \& Spears, D. (2019). Quantifying India’s Climate Vulnerability. In India Policy Forum (Vol. 15, No. 1, pp. 107-148). National Council of Applied Economic Research.

30. Mora, C., Dousset, B., Caldwell, I. R., Powell, F. E., Geronimo, R. C., Bielecki, C. R., ... \& Lucas, M. P. (2017). Global risk of deadly heat. Nature Climate Change, 7(7), nclimate 3322 
31. Nicholas, K., Campbell, L., Paul, E., Skeltis, G., Wang, W., \& Gray, C. (2021). Climate anomalies and childhood growth in Peru. Population and Environment, 1-22.

32. Nobles, J., \& Hamoudi, A. (2019). Detecting the Effects of Early-Life Exposures: Why Fecundity Matters. Population Research and Policy Review, 38(6), 783-809.

33. Nordkvelle, J., Rustad, S. A., \& Salmivalli, M. (2017). Identifying the effect of climate variability on communal conflict through randomization. Climatic Change, 141(4), 627639.

34. Ramakrishnan, U., Grant, F., Goldenberg, T., Zongrone, A., \& Martorell, R. (2012). Effect of women's nutrition before and during early pregnancy on maternal and infant outcomes: a systematic review. Paediatric and perinatal epidemiology, 26, 285-301.

35. Randell, H., Gray, C., \& Grace, K. (2020). Stunted from the start: Early life weather conditions and child undernutrition in Ethiopia. Social Science \& Medicine, 261, 113234.

36. Ray, D. K., West, P. C., Clark, M., Gerber, J. S., Prishchepov, A. V., \& Chatterjee, S. (2019). Climate change has likely already affected global food production. PloS one, 14(5), e0217148.

37. Rayco-Solon, P., Fulford, A. J., \& Prentice, A. M. (2005). Maternal preconceptional weight and gestational length. American journal of obstetrics and gynecology, 192(4), 1133-1136.

38. Schwarzenberg, S. J., \& Georgieff, M. K. (2018). Advocacy for improving nutrition in the first 1000 days to support childhood development and adult health. Pediatrics, 141(2).

39. Shively, G., Sununtnasuk, C., \& Brown, M. (2015). Environmental variability and child growth in Nepal. Health \& Place, 35, 37-51.

40. Shively, G. E. (2017). Infrastructure mitigates the sensitivity of child growth to local agriculture and rainfall in Nepal and Uganda. Proceedings of the National Academy of Sciences, 114(5), 903-908.

41. Shrimpton, R., Victora, C. G., de Onis, M., Lima, R. C., Blössner, M., \& Clugston, G. (2001). Worldwide timing of growth faltering: implications for nutritional interventions. Pediatrics, 107(5), e75-e75.

42. Spears, D. (2018). Exposure to open defecation can account for the Indian enigma of child height. Journal of Development Economics, 102277.

43. Ssewanyana, S. (2003). Food security and child nutrition status among urban poor households in Uganda: Implications for poverty alleviation. African Economic Research Consortium.

44. Thiede, B. C., \& Gray, C. (2020). Climate exposures and child undernutrition: Evidence from Indonesia. Social Science \& Medicine, 265, 113298.

45. Tiwari, S., Jacoby, H. G., \& Skoufias, E. (2017). Monsoon babies: rainfall shocks and child nutrition in Nepal. Economic Development and Cultural Change, 65(2), 167-188. 
46. UNICEF, W., World Health Organization, \& UNICEF. (2012). Progress on drinking water and sanitation: 2012 update. United States: WHO/UNICEF Joint Monitoring Programme for Water Supply and Sanitation.

47. Victora, C. G., De Onis, M., Hallal, P. C., Blössner, M., \& Shrimpton, R. (2010). Worldwide timing of growth faltering: revisiting implications for interventions. Pediatrics, 125(3), e473-e480. 
Table 1. Descriptive statistics for the predictors and outcomes $(\mathrm{N}=222,572)$.

\begin{tabular}{|c|c|c|c|c|}
\hline Variable & Mean & Std. Dev. & Min. & Max. \\
\hline \multicolumn{5}{|l|}{ Demographics - Child } \\
\hline Height for age (HAZ) & -1.88 & 1.53 & -6 & 5.99 \\
\hline Stunted & 0.47 & 0.50 & 0 & 1 \\
\hline Severely stunted & 0.21 & 0.41 & 0 & 1 \\
\hline Child's age (months) & 40.58 & 10.34 & 24 & 59 \\
\hline Child is a girl & 0.48 & 0.50 & 0 & 1 \\
\hline Child is a twin & 0.01 & 0.11 & 0 & 1 \\
\hline Child's birth order & 2.50 & 1.70 & 1 & 17 \\
\hline Born in clinic & 0.71 & 1.15 & 0 & 1 \\
\hline \multicolumn{5}{|l|}{ Demographics - Family } \\
\hline Mother's age at child's birth & 27.86 & 5.37 & 15 & 49 \\
\hline Mother is married & 0.98 & 0.13 & 0 & 1 \\
\hline \multicolumn{5}{|l|}{ Mother's education level } \\
\hline None (reference) & 0.38 & 0.48 & 0 & 1 \\
\hline Primary & 0.17 & 0.37 & 0 & 1 \\
\hline Secondary & 0.38 & 0.49 & 0 & 1 \\
\hline Higher & 0.08 & 0.27 & 0 & 1 \\
\hline Children ever born & 2.92 & 1.72 & 1 & 17 \\
\hline Improved toilet & 0.56 & 0.51 & 0 & 1 \\
\hline Rural & 0.73 & 0.44 & 0 & 1 \\
\hline \multicolumn{5}{|l|}{ Climate - anomalies } \\
\hline Prenatal precipitation $(\mathrm{mm})$ & 109.17 & 63.85 & 0.60 & 448.65 \\
\hline Prenatal temperature (C) & 23.60 & 5.43 & -2.38 & 30.91 \\
\hline $1^{\text {st }}$ year precipitation $(\mathrm{mm})$ & 108.14 & 50.77 & 1.84 & 340.72 \\
\hline $1^{\text {st }}$ year temperature $(\mathrm{C})$ & 23.45 & 5.19 & 0.09 & 28.47 \\
\hline $2^{\text {nd }}$ year precipitation $(\mathrm{mm})$ & 106.57 & 50.38 & 1.84 & 335.39 \\
\hline $2^{\text {nd }}$ year temperature $(C)$ & 23.47 & 5.17 & 0.90 & 28.36 \\
\hline Prenatal precipitation anomaly & 0.10 & 1.03 & -2.32 & 3.20 \\
\hline Prenatal temperature anomaly & 0.13 & 0.92 & -2.26 & 2.43 \\
\hline $1^{\text {st }}$ year precipitation anomaly & 0.16 & 0.92 & -3.61 & 3.10 \\
\hline $1^{\text {st }}$ year temperature anomaly & 0.05 & 0.64 & -2.13 & 1.94 \\
\hline $2^{\text {nd }}$ year precipitation anomaly & 0.06 & 0.91 & -3.57 & 3.07 \\
\hline $2^{\text {nd }}$ year temperature anomaly & 0.07 & 0.49 & -1.71 & 2.32 \\
\hline \multicolumn{5}{|l|}{ Climate - extreme days } \\
\hline Prenatal wet days & 15.30 & 7.57 & 0 & 40 \\
\hline Prenatal dry days & 68.21 & 39.99 & 1 & 247 \\
\hline Prenatal hot days & 15.11 & 10.87 & 0 & 51 \\
\hline Prenatal cold days & 14.23 & 9.22 & 0 & 45 \\
\hline $1^{\text {st }}$ year wet days & 20.11 & 5.92 & 0 & 41 \\
\hline $1^{\text {st }}$ year dry days & 87.20 & 50.49 & 4 & 308 \\
\hline $1^{\text {st }}$ year hot days & 19.94 & 9.19 & 0 & 53 \\
\hline $1^{\text {st }}$ year cold days & 20.22 & 7.86 & 0 & 60 \\
\hline $2^{\text {nd }}$ year wet days & 19.15 & 5.99 & 1 & 41 \\
\hline $2^{\text {nd }}$ year dry days & 84.12 & 51.74 & 3 & 308 \\
\hline $2^{\text {nd }}$ year hot days & 21.88 & 8.50 & 0 & 60 \\
\hline $2^{\text {nd }}$ year cold days & 21.04 & 9.57 & 0 & 60 \\
\hline
\end{tabular}


Figure 1. Proportion stunted among children ages 2-5 years, by province (Bangladesh 2014, India 201516, Nepal 2016, Pakistan 2017-18).

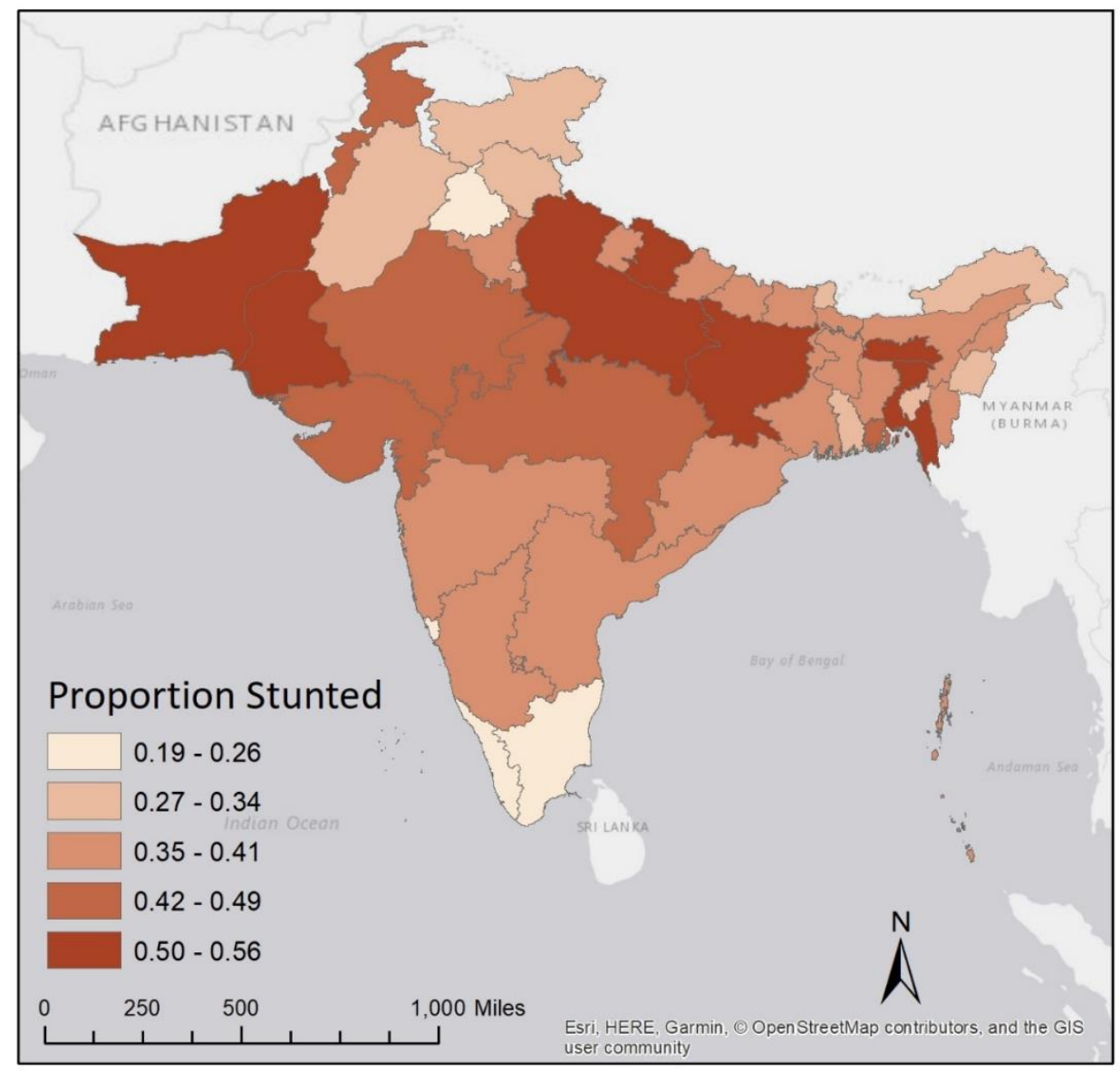


Table 2. Main regression results with alternative climate specifications.

\begin{tabular}{|c|c|c|c|c|c|c|}
\hline \multirow{2}{*}{$\begin{array}{l}\text { Variable } \\
\text { Climate - }^{\text {anomalies }}{ }^{1}\end{array}$} & \multicolumn{2}{|l|}{ HAZ } & \multicolumn{2}{|l|}{ Stunting } & \multicolumn{2}{|c|}{ Severe Stunting } \\
\hline & & & & & & \\
\hline Prenatal precip. anomaly & -0.013 & & 1.007 & & 0.995 & \\
\hline Prenatal temp. anomaly & -0.009 & & 0.982 & & 0.971 & \\
\hline $1^{\text {st }}$ year precip. anomaly & -0.024 & * & 1.031 & $* *$ & 1.024 & * \\
\hline $1^{\text {st }}$ year temp. anomaly & 0.018 & & 0.966 & + & 0.965 & \\
\hline $2^{\text {nd }}$ year precip. anomaly & -0.012 & & 1.019 & & 1.031 & * \\
\hline $2^{\text {nd }}$ year temp. anomaly & 0.027 & + & 0.977 & & 0.988 & \\
\hline \multicolumn{7}{|l|}{ Demographics - Child } \\
\hline Child's age (months) & -0.020 & $* * *$ & 1.025 & $* * *$ & 1.006 & \\
\hline Child's age squared & 0.000 & $* * *$ & 1.000 & $* * *$ & 1.000 & * \\
\hline Child is a girl & -0.007 & & 1.032 & + & 1.022 & \\
\hline Child is a twin & -0.230 & $* * *$ & 1.330 & $* * *$ & 1.480 & $* * *$ \\
\hline Child's birth order & -0.102 & $* * *$ & 1.131 & $* * *$ & 1.126 & $* * *$ \\
\hline Born in clinic & 0.103 & $* * *$ & 0.871 & $* * *$ & 0.838 & $* * *$ \\
\hline \multicolumn{7}{|l|}{ Demographics - Family } \\
\hline Mother's age at child's birth & 0.075 & $* * *$ & 0.911 & $* * *$ & 0.921 & $* * *$ \\
\hline Mother's age squared & -0.001 & $* * *$ & 1.001 & $* * *$ & 1.001 & $* * *$ \\
\hline \multicolumn{7}{|l|}{ Mother's education level } \\
\hline Primary & 0.124 & $* * *$ & 0.851 & $* * *$ & 0.765 & $* * *$ \\
\hline Secondary & 0.367 & $* * *$ & 0.607 & $* * *$ & 0.533 & $* * *$ \\
\hline Higher & 0.710 & $* * *$ & 0.375 & $* * *$ & 0.329 & $* * *$ \\
\hline Mother is married & 0.017 & & 0.946 & & 0.996 & \\
\hline Children ever born & 0.010 & & 0.992 & & 1.002 & \\
\hline Improved toilet & 0.199 & $* * *$ & 0.757 & $* * *$ & 0.761 & $* * *$ \\
\hline Rural & -0.084 & $* *$ & 1.096 & $* *$ & 1.009 & \\
\hline $\mathbf{N}$ & 222572 & & 222572 & & 222572 & \\
\hline Joint test of climate effects & 5.10 & $* * *$ & 27.31 & $* * *$ & 23.38 & $* * *$ \\
\hline \multicolumn{7}{|l|}{ Climate - extreme days ${ }^{2}$} \\
\hline Prenatal wet days & -0.003 & ** & 1.001 & & 1.003 & \\
\hline Prenatal dry days & -0.001 & & 1.000 & & 1.000 & \\
\hline Prenatal hot days & -0.001 & & 1.000 & & 1.001 & \\
\hline Prenatal cold days & 0.000 & & 1.000 & & 0.999 & \\
\hline $1^{\text {st }}$ year wet days & -0.006 & $* * *$ & 1.006 & $* * *$ & 1.004 & $* * *$ \\
\hline $1^{\text {st }}$ year dry days & -0.003 & $* * *$ & 1.002 & ** & 1.002 & * \\
\hline $1^{\text {st }}$ year hot days & 0.001 & & 0.999 & & 0.999 & \\
\hline $1^{\text {st }}$ year cold days & 0.000 & & 0.998 & & 0.996 & ** \\
\hline $2^{\text {nd }}$ year wet days & -0.001 & & 1.000 & & 1.000 & \\
\hline $2^{\text {nd }}$ year dry days & 0.001 & * & 0.998 & $* *$ & 0.998 & $*$ \\
\hline $2^{\text {nd }}$ year hot days & 0.000 & & 1.000 & & 1.000 & \\
\hline $2^{\text {nd }}$ year cold days & -0.001 & & 1.001 & & 1.001 & \\
\hline $\mathbf{N}$ & 221946 & & 221946 & & 221946 & \\
\hline Joint test of climate effects & 13.55 & $* * *$ & 151.48 & $* * *$ & 53.03 & $* * *$ \\
\hline
\end{tabular}

${ }^{1}$ Anomalies specification: Constant, province indicators, month of birth indicators, born in clinic missing indicator, and a time trend term are included in the model but not shown.

${ }^{2}$ Extreme days specification: Controls, constant, province indicators, month of birth indicators, missing indicators, and the time trend term are included in the model but not shown. 
Figure 2. Statistically significant nonlinear effects of climate anomalies on stunting.
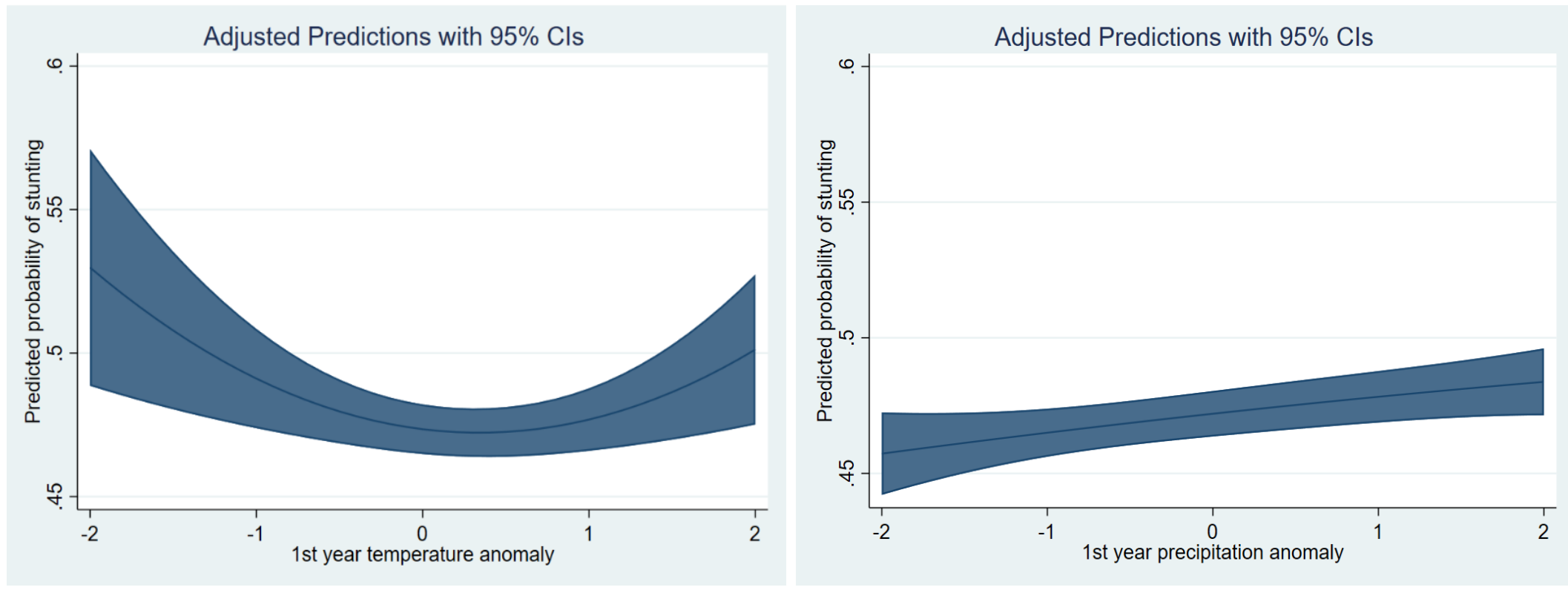
Table 3. Statistically significant interactive effects of climate anomalies on stunting.

\begin{tabular}{|c|c|c|c|c|c|c|}
\hline \multirow[t]{2}{*}{ Variable } & \multicolumn{2}{|c|}{ Prenatal anomalies } & \multicolumn{2}{|c|}{$1^{\text {st }}$ year anomalies } & \multicolumn{2}{|c|}{$2^{\text {nd }}$ year anomalies } \\
\hline & Precip. & Temp. & Precip. & Temp. & Precip. & Temp. \\
\hline \multicolumn{7}{|l|}{ Toilet quality } \\
\hline Unimproved & $0.979+$ & $0.970 *$ & $1.042 * * *$ & $0.968+$ & $1.040 *$ & $0.947 *$ \\
\hline Improved & 0.990 & 0.998 & 1.013 & 1.001 & 0.994 & 0.972 \\
\hline \multicolumn{7}{|l|}{ Mother's education } \\
\hline None & $0.965 * *$ & $0.969+$ & $1.040 * *$ & $0.952 *$ & 1.022 & $0.928 *$ \\
\hline Primary & $0.975+$ & 1.024 & 1.018 & 1.012 & 0.983 & 0.953 \\
\hline Secondary & 1.000 & 0.993 & 1.009 & 0.982 & $1.043 *$ & 1.004 \\
\hline Higher & 0.997 & 0.964 & $1.049+$ & $1.091+$ & 0.956 & 0.954 \\
\hline \multicolumn{7}{|l|}{ Country of residence } \\
\hline Bangladesh & 1.011 & 0.999 & 0.987 & 0.998 & 0.966 & 0.977 \\
\hline India & $0.983 *$ & $0.983+$ & $1.029 * *$ & 0.975 & 1.022 & $0.936 * *$ \\
\hline Nepal & 0.974 & 0.961 & 1.034 & $0.914 * *$ & 1.021 & 1.045 \\
\hline Pakistan & 1.039 & $1.047 *$ & 1.050 & $1.359 * * *$ & $0.967+$ & $1.130 * *$ \\
\hline \multicolumn{7}{|l|}{ Caste/Tribe } \\
\hline Scheduled Caste & 0.987 & 0.967 & $1.040 *$ & 0.963 & $1.070 *$ & 0.961 \\
\hline Scheduled Tribe & 0.974 & 0.994 & 1.044 & $0.929 *$ & $1.085 *$ & 1.054 \\
\hline Other & $0.979 *$ & 0.991 & $1.023 *$ & 0.968 & 1.000 & $0.915 * * *$ \\
\hline
\end{tabular}

Each header presents results from one regression that includes interactions between that variable and the climate anomalies. The regressions additionally include all terms from specification 1 in Table 2. Caste/tribe includes India only $(\mathrm{N}=184176)$. Interactions with child sex and urbanicity were also tested but were not jointly significant.

$+\mathrm{p}<0.10,{ }^{*} \mathrm{p}<0.05, * * \mathrm{p}<0.01, * * * \mathrm{p}<0.001$. 